\title{
Characterisation of osteoprotegerin autoantibodies in coeliac disease
}

\author{
Ana Real ${ }^{1}$ \\ Nick Gilbert ${ }^{2}$ \\ Barbara Hauser ${ }^{1}$ \\ Nick Kennedy ${ }^{1}$ \\ Alan Shand ${ }^{3}$ \\ Helen Gillett ${ }^{3}$ \\ Peter Gillett ${ }^{3}$ \\ Clive Goddard ${ }^{3}$ \\ Ángel Cebolla ${ }^{5}$, \\ Carolina Sousa ${ }^{4}$ \\ William D Fraser ${ }^{6}$ \\ Jack Satsangi ${ }^{1,3}$ \\ Stuart H Ralston ${ }^{1}$ \\ Philip L Riches ${ }^{1}$
}

${ }^{1}$ Centre for Genomics and Experimental Medicine, IGMM, Edinburgh UK, ${ }^{2}$ Human Genetics Unit, IGMM, Edinburgh, UK ${ }^{3}$ Gastroenterology Department, Lothian University Hospitals NHS Trust, Edinburgh, UK ${ }^{4}$ Departamento de Microbiología y Parasitología, Facultad de Farmacia, Universidad de Sevilla, Sevilla, Spain ${ }^{5}$ Biomedal SL, Sevilla, Spain ${ }^{6}$ University of East Anglia, Norwich UK

Correspondence to:

Dr Philip L Riches

Centre for Genomics and Experimental Medicine,

Institute of Genetics and Molecular Medicine,

Edinburgh EH4 2XU,

UK

Phone: +44-131-651-1022

Fax: +44-131-651-1085

Email: priches@staffmail.ed.ac.uk 


\begin{abstract}
Objectives

Autoantibodies neutralising the effect of the bone regulatory cytokine osteoprotegerin (OPG) have been described in a patient with severe osteoporosis and coeliac disease. This study aimed to determine the prevalence and epitope specificity of autoantibodies to OPG in patients with coeliac disease, and correlate their presence with bone mineral density.
\end{abstract}

\title{
Methods
}

A direct enzyme linked immunosorbent assay was developed and used to screen patients with coeliac disease for autoantibodies to OPG. Recombinant fragments of OPG were made to evaluate the epitope specificity and affinity of these antibodies. Phenotype information of the patients was obtained by case note review.

\section{Results}

Raised titres of antibodies to OPG were found in 7/71 (9.8\%) patients with coeliac disease, compared with $1 / 72(1.4 \%)$ non-coeliac osteoporosis clinic control patients $(p<0.05)$. Our results suggest a polyclonal antibody response to OPG is raised in these patients capable of recognising different epitopes of OPG with varying affinity. The titre of OPG antibodies was associated with lower bone mineral density $\mathrm{Z}$ score of the hip in coeliac patients on univariate $(\mathrm{p}<0.05)$ and multivariate analysis including age, sex height and weight as covariates $(\mathrm{p}<0.01)$.

\section{Conclusion}

Polyclonal antibodies to OPG are more common in patients with coeliac disease and are independently associated with lower bone mineral density $\mathrm{Z}$ scores of the hip. Further work is required to establish the clinical utility of testing for OPG antibodies. 


\section{Introduction}

Autoantibodies to endogenous cytokines are increasingly recognised as a cause of disease pathogenesis (1). Autoantibodies neutralising the bone regulatory cytokine osteoprotegerin (OPG) have previously been described in a patient with severe osteoporosis and an incidental finding of autoimmune thyroid and coeliac disease (2). OPG acts as a decoy receptor for the receptor activator of NFkB ligand (RANKL) leading to inhibition of osteoclast differentiation and reducing bone resorption (3-5). The importance of this pathway in bone metabolism is demonstrated by the fact that pharmacological blockade of RANKL is an effective treatment for osteoporosis (6) and that loss of function mutations of OPG in humans lead to raised bone turnover and multiple fractures in childhood (7).

Whilst osteoporosis is a common complication of many autoimmune diseases it is typically attributed to disease specific factors or steroid treatment rather than a direct autoimmune process $(8,9)$. In coeliac disease up to $20-50 \%$ of newly diagnosed patients have reduced bone density, which is usually attributed to associated malabsorption and secondary calcium and vitamin D deficiencies, or to gut inflammation and the release of pro-inflammatory cytokines, though the severity of osteoporosis often bears little relation to the severity of the underlying coeliac disease (9-12). A gluten-free diet, the only available treatment for coeliac patients, improves bone mass and, consequently, reduces fracture risk, although the co-administration of mineral active drugs may be useful in a subgroup of coeliac disease patients (13). In the index patient with neutralizing OPG antibodies the osteoporosis did not respond to a gluten free diet, though there was a remarkable normalisation of bone mineral density in response to inhibition of bone turnover with intravenous bisphosphonate therapy. Therefore OPG antibodies seem to be associated with the development of high bone turnover osteoporosis, but whether they commonly contribute to the pathogenesis of osteoporosis in patients with coeliac disease remains to be determined.

In this study, we have developed an enzyme linked immunosorbent assay for osteoprotegerin antibodies using whole or partial recombinant OPG and used this to determine the prevalence and epitope specificity of OPG antibodies in a cohort of patients with coeliac disease. 


\section{Materials and Methods}

\subsection{Subjects}

Subjects were recruited from coeliac disease or osteoporosis clinics in NHS Lothian with approval of the local ethics committee. Bone density in all patients was determined by dual X-ray absorptiometry using a Hologic QDR4500 densitometer. Since many of the patients were men under the age of 50, or premenopausal women, we report both the bone density $\mathrm{Z}$ score and $\mathrm{T}$ score in line with current recommendations(14). A total of 71 adult coeliac patients were included in the study (57/71 female (80\%); median age 54 (range 23 to 83 years, interquartile range (IQR) 19 years). 20 patients were within 2 years of diagnosis (median disease duration 2 months (range 7 days to 19 months, IQR 9 months) with 51 patients having disease duration $>2$ years (median disease duration 13 years, range 2 to 45 years, IQR 9 yrs). All patients were diagnosed with coeliac disease by a gastroenterology consultant based on the detection of IgA anti-tissue transglutaminase antibodies in serum, and confirmed by a small intestinal biopsy. 17/71 coeliac patients (24\%) had osteoporosis, 32/71 (45\%) had osteopenia and 22/71 (31\%) had normal bone density T scores. 72 control patients $(60 / 72$ female (82\%), median age 70 (range 22 to 93 years, IQR 17.5 years) were recruited when attending an osteoporosis clinic, and were confirmed to be negative for tissue transglutaminase antibodies on routine screening. $41 / 72(\%)$ of the osteoporosis clinic patients were confirmed as having osteoporosis on their most recent bone density scan, 25/72 (35\%) had osteopenia and 6/72 (8\%) had normal bone density. A reference range for OPG antibodies was derived from 22 healthy volunteers with no known underlying disease.

\subsection{Recombinant human Osteoprotegerin cloning}

The coding sequence of human OPG was amplified from an IMAGE clone template (NCBI accession: BC030155.2, IMAGE: 4875170) with Q5 Hot Start High-Fidelity DNA Polymerase (New England Biolabs, Massachusetts, USA) using three pairs of primers designed to clone and express three fragments covering the entire OPG protein (Table 1). The forward primers include a $B g l I I$ restriction site, and the reverses include the site for XhoI. The PCR products were digested with $B g l \mathrm{II}$ and $\mathrm{XhoI}$ restriction endonucleases and purified before ligation into the expression vector pET32a (Novagen, Darmstadt, Germany). In this vector target genes are cloned under the control of a bacteriophage T7 promoter and the resulting peptides are fused with the 109aa $\operatorname{Trx} \bullet \operatorname{Tag}^{\mathrm{TM}}$ thioredoxin 
protein. The resulting recombinant plasmids were designated pET-OPG1, 2 and 3 . The DNA sequences for all constructs were verified by enzyme digestion and DNA sequencing.

\subsection{Protein expression and purification}

The pET-OPG plasmids were transformed into Escherichia coli BL21 (DE3) RP competent cells for protein expression. The transformed cells were grown in Luria broth (LB) with $34 \mu \mathrm{g} / \mathrm{ml}$ chloramphenicol and $100 \mu \mathrm{g} / \mathrm{ml}$ ampicillin at $37{ }^{\circ} \mathrm{C}$ and protein expression was induced with a final concentration of $100 \mu \mathrm{M}$ Isopropyl $\beta$-D-1thiogalactopyranoside (IPTG) once the $\mathrm{OD}_{600}$ had reached 0.6-0.8. The temperature was lowered to $25{ }^{\circ} \mathrm{C}$ and the bacterial cell culture was incubated for a further $6 \mathrm{~h}$ for protein expression.

The cell pellet was harvested by centrifugation at $5000 \mathrm{rpm}$ for $15 \mathrm{~min}$ at $4{ }^{\circ} \mathrm{C}$. The cells were resuspended in 5 volumes of binding buffer $(300 \mathrm{mM} \mathrm{NaCl}, 15 \mathrm{mM}$ Imidazole, 50 $\mathrm{mM}$ Tris- $\mathrm{HCl} \mathrm{pH} 8,10 \%$ Glycerol, $10 \mathrm{mM} \beta$-Mercaptoethanol, $250 \mu \mathrm{M}$ Phenyl methyl sulfonyl fluoride) containing EDTA-free protease inhibitor tablet (Roche, Basel, Switzerland). After the cells were freeze-thawed twice on dry-ice, they were digested with $1 \mathrm{mg} / \mathrm{ml}$ Lysozyme for $30 \mathrm{~min}$ on ice. Cells were then extensively sonicated and the lysate was clarified by centrifugation at $16000 \mathrm{~g}$ at $4{ }^{\circ} \mathrm{C}$ for $30 \mathrm{~min}$. The supernatant was mixed with $2 \mathrm{ml}$ of Ni-NTA Agarose (Qiagen, Hilden, Germany), pre-washed in binding buffer, and incubated $1 \mathrm{~h}$ on a roller at room temperature (RT). The resin was centrifuged at $3000 \mathrm{x} \mathrm{g}$ for $5 \mathrm{~min}$ and washed three times by gentle inversion with $10 \mathrm{ml}$ of wash buffer (binding buffer $+5 \mathrm{mM}$ Imidazole). The suspension was transferred into a column with wash buffer and the flow-through was collected and loaded into the column a second time. The column was then washed three times with $10 \mathrm{ml}$ of wash buffer, and protein was eluted with elution buffer $(300 \mathrm{mM} \mathrm{NaCl}, 250 \mathrm{mM}$ Imidazole, $50 \mathrm{mM}$ Tris- $\mathrm{HCl} \mathrm{pH}$ 8, $250 \mu \mathrm{M}$ Phenyl methyl sulfonyl fluoride (PMSF), $10 \mathrm{mM} \beta$-Mercaptoethanol). $1 \mathrm{ml}$ fractions of eluate were collected from the column.

\subsection{SDS-PAGE and Western Blot analysis}

The eluted fractions were analyzed for yield and purity on sodium dodecyl sulfatepolyacrylamide gel electrophoresis (SDS-PAGE). Protein samples were mixed with $2 \mathrm{X}$ SDS-PAGE loading buffer and boiled for $5 \mathrm{~min}$ at $100{ }^{\circ} \mathrm{C}$; $10 \mu \mathrm{l}$ of lysate, wash and 
eluted fractions were analyzed. Separated proteins were Coomassie blue stained and the fractions containing protein were pooled and dialyzed overnight against TEN10P buffer (10 mM Tris-HCl pH 7.5, 1 mM EDTA, 10 mM NaCl, $250 \mu \mathrm{M}$ PMSF, 0.05\% NP40). Dialyzed protein was quantified by Qubit ${ }^{\circledR} 2.0$ Fluorometer (Invitrogen, Paisley, UK) and stored in aliquots with $10 \%$ glycerol at $-20^{\circ} \mathrm{C}$ or analyzed by Western blotting.

Separated proteins by SDS-PAGE were transferred to a polyvinylidene fluoride (PVDF) membrane. The PVDF membranes were incubated with anti-His monoclonal antibody (Sigma, Missouri, USA) or anti-OPG polyclonal antibody (Abcam, Cambridge, UK). After washing, horseradish peroxidase (HRP) conjugated anti-mouse or anti-rabbit IgG antibody (Jackson ImmunoResearch, Philadelphia, USA) was added. Immunoreactive protein bands were detected with the SuperSignal system (Pierce, Illinois, USA) according to the manufacturer's instructions.

\subsection{Direct enzyme-linked immunosorbent assay (ELISA)}

Maxisorp microtiter plates (Greiner Bio-One, Frickenhausen, Germany) were coated with $0.1 \mu \mathrm{g} /$ well of OPG or partial recombinant OPG (R\&D Systems, Minnesota, USA) in 0.2 $\mathrm{M}$ of $\mathrm{Na}_{2} \mathrm{CO}_{3}-\mathrm{NaHCO}_{3}\left(\mathrm{pH}\right.$ 9.6), and incubated overnight at $4^{\circ} \mathrm{C}$. After the coating solution was removed, the wells were washed with phosphate-buffered saline (PBS) containing $0.05 \%$ Tween-20 (washing buffer) and blocked with blocking solution (PBS with 3\% nonfat dry milk) for 1 hour at RT. Serum samples were diluted 1:1,000 in PBS$3 \%$ bovine serum albumin (BSA) and added to the wells. After $1 \mathrm{~h}$ of incubation at RT, the plates were washed and HRP-conjugated goat anti-human IgG diluted 1:10,000 (Jackson ImmunoResearch) was added. After 1 hour of incubation at RT, the plates were washed and $100 \mu \mathrm{L}$ per well of substrate solution (TMB liquid substrate system, Sigma) was added. After incubation for $30 \mathrm{~min}$ at RT in the dark, color development was stopped with $100 \mu \mathrm{L}$ per well of stop solution (KPL, Maryland, USA) and the absorbance was measured at $450 \mathrm{~nm}$. Two separate assays were performed, each with two repetitions.

\subsection{Competitive enzyme-linked immunosorbent assay}

Maxisorp microtiter plates (Greiner Bio-One) were coated with $0.1 \mu \mathrm{g} / \mathrm{well}$ of OPG or partial recombinant OPG in $0.2 \mathrm{M}$ of $\mathrm{Na}_{2} \mathrm{CO}_{3}-\mathrm{NaHCO}_{3}$ (pH 9.6), and incubated overnight at $4^{\circ} \mathrm{C}$. Plates were washed with washing buffer and blocked with blocking solution for 1 hour at RT. Serial dilutions of OPG and partial recombinant OPG were made in PBS- 
$3 \% \mathrm{BSA}$, to each of which was added the corresponding serum solution $(1: 1,000$ in PBS$3 \% \mathrm{BSA})$. The samples were pre-incubated 2 hour at RT with gentle mixing and then added to the wells. After $1 \mathrm{~h}$ of incubation at RT, the plates were washed and incubated for 1 hour at RT with anti-human IgG-HRP 1:10,000. Plates were washed again and the substrate solution was added. The reaction was stopped after dark incubation for $30 \mathrm{~min}$ at RT and the absorbance at $450 \mathrm{~nm}$ was measured. Two separate assays were performed, each with two repetitions.

\subsection{Statistical analysis}

Direct ELISA. All serum samples represent the mean of duplicate assays conducted on two different days, with a coefficient of variation of $12 \%$ between assays, and $6 \%$ within assays noted. A reference (antigen without serum) was included in each assay. Positive samples were defined a priori to be greater than the mean of healthy controls plus 2 standard deviations (SD) which would be expected to define approximately $95 \%$ of a normal population. Statistical analysis was performed with the software package Minitab 16.2.4 (Minitab Inc., State College PA, USA). The differences between groups were examined by Mann-Whitney $U$ test for absolute OPG antibody readings (samples not normally distributed), and Fishers Exact test for categorical analyses of positive or negative samples. General regression analysis was performed in Minitab specifying bone mineral density as the response, with age, height, weight and OPG antibody titre entered as continuous variables, and sex as a categorical variable. The significance, regression coefficient and 95\% confidence intervals for the regression coefficient are reported.

Competitive ELISA. The OPG and partial recombinant OPG curves were obtained by plotting percentage maximum absorbance against logarithm of protein concentration. The Sigma Plot 11.0 program (Systat Software) was used to calculate $\mathrm{IC}_{50}$ and the crossreactivity $(\mathrm{CR})$ for the protein or fragments. $\mathrm{The} \mathrm{IC}_{50}$ is defined as the concentration that produces a reduction of $50 \%$ in the peak signal in the ELISA. The CR was determined as ( $\mathrm{IC}_{50}$ of the protein or fragment that presents the greatest affinity for antibodies/ $\mathrm{IC}_{50}$ of each protein or fragment assayed) x 100 .

\section{Results}

\subsection{Prevalence of autoantibodies against osteoprotegerin in coeliac patients}


OPG antibody levels were determined by direct ELISA in serum samples from 71 patients with coeliac disease and 72 non-coeliac osteoporosis clinic controls (Figure 1A). A skewed distribution was observed with an excess of both elevated and low level/undetectable results obtained. Defining high titre positivity for OPG antibodies arbitrarily as having a value greater than the mean plus 2 SD of healthy subjects $(0.56)$ gives a prevalence of $7 / 71(9.8 \%)$ in coeliac patients, compared to $1 / 72(1.4 \%)$ in the control cohort ( $\mathrm{p}<0.05$, Fishers Exact, two sided). Conversely among the coeliac patients just 2/71 (2.8\%) had undetectable levels of OPG antibody compared to 20/72 (27.8\%) in the osteoporosis controls ( $\mathrm{p}<0.001$, Fishers Exact, two sided). These results suggest that OPG antibodies are significantly more common in coeliac patients than in the non-coeliac osteoporosis clinic controls. Similarly the median OPG antibody level by direct ELISA in coeliac patients was 0.09 units (Interquartile range (IQR) 0.16), and in osteoporosis clinic controls 0.02 units (IQR range 0.06) $(\mathrm{p}<0.001$ Mann-Whitney $U$ test). No significant difference in the antibody titre was observed between patients within 2 years of diagnosis or those $>2$ years from diagnosis $(\mathrm{p}=0.47$ Mann-Whitney $U$ test $)$.

A summary of the characteristics of patients with raised OPG antibody titres is given in Table 2 though we acknowledge that the small sample size in this study limits the conclusions that it is possible to draw. No significant difference between the groups in terms of conventional risk factors for osteoporosis is seen and similarly no significant difference was observed in the small number of patients reporting steroid exposure $(n=2)$ or concomitant autoimmune disease $(n=3)$. Patients with raised OPG antibody levels had lower BMD $\mathrm{T}$ and $\mathrm{Z}$ scores though this did not reach statistical significance in a case control analysis ( $\mathrm{p}$ values represent 2 sided student T-test for continuous variables or Fishers Exact test for categorical variables). This trend is not contributed to by treatment effects since a greater proportion of patients with raised OPG antibodies were receiving anti-resorptive therapy. In a univariate regression analysis the titre of OPG antibody is significantly associated with total hip BMD Z score $(\mathrm{p}=0.039$, regression coefficient 0.49 [-0.94 - -0.03]) (Figure 1B) but not spine BMD Z score $(\mathrm{p}=0.49$, regression coefficient $-0.21[-0.80-0.39])$. Multivariate regression analysis including age, sex, height and weight as covariates strengthens the association of OPG antibody titre with total hip BMD Z score ( $<<0.01$, regression coefficient -0.58 [-0.99 - -0.17]) though spine BMD Z score remains not significant ( $\mathrm{p}=0.33$, regression coefficient -0.27 [ $-0.84-0.29]$ ). Within the control cohort no association between titre of antibody and bone density was 
observed. An arbitrary threshold of mean plus 2 standard deviations of levels seen in healthy controls does not identify a population that is more likely to have osteoporosis, though we did observe that the two patients within this group with the highest titre of antibody were both osteoporotic. These results are compatible with a role for OPG antibodies in the pathogenesis of osteoporosis in a small number of patients with coeliac disease though must be interpreted with caution in view of the small sample size.

\subsection{Expression and purification of Osteoprotegerin recombinant fragments}

With the aim of evaluating the epitope specificity of OPG antibodies three pairs of primers were used to amplify and clone three different peptide fragments covering the full OPG protein (Table 1). These primers were designed on the basis of the OPG structure which consists of 7 structural domains (Figure 2A). The recombinant plasmids pET-OPG1 and pET-OPG2 express the amino-terminal cysteine rich domains (D1-D4) which are necessary for binding to RANKL $(15,16)$. The third recombinant plasmid, pETOPG3, was designed to express the carboxy-terminal portion of the protein that contains two putative death domain homologous regions (D5 and D6) which have been related to cytotoxic signals in mammalian cells $(15,17)$, and a heparin-binding region (D7). To verify protein expression we analyzed the whole cell extract by anti-His monoclonal antibody $(\mathrm{moAb})$ immunoblotting. The $E$. coli cultures transformed with pET-OPG1 and pET-OPG2 expressed the OPG fragments with the size expected (Figure 2B), however the cell extract from pET-OPG3 cultures showed lots of degradation products (data not shown). These results suggested the carboxy-terminal region interferes with the survival of $E$. coli cells and leads to bacteria death or promotes significant defects in bacteria growth that dramatically decrease expression capabilities. Therefore, this region could not be expressed in E. coli cultures.

In order to confirm the correct expression of pET-OPG1 and pET-OPG2 plasmids, another antibody specific for the OPG protein was used to analyze the different fragments (Figure $2 \mathrm{C}$ ). The results obtained with anti-OPG polyclonal antibody (pAb) demonstrate that this antibody was able to detect the same protein fragments as the anti-His moAb. At the same time, these results confirmed the correct expression of OPG recombinant fragments. 
The recombinant partial proteins (OPG1 and OPG2) contain a His tag, therefore, Ni-NTA agarose (Qiagen) was used to purify them. The eluted fractions were almost entirely free of contaminating proteins as visualized by Coomassie staining (Figure 3A). To confirm these results with specific antibodies against fragments of interest, the positive fractions eluted were pooled and immunoblotting electrophoresis analyses were performed. As shown in figure $3 \mathrm{~B}$, anti-His moAb and anti-OPG pAb had affinity for a single band in the pooled eluate. Altogether, these results verified the expression and purification process of the OPG recombinant fragments.

\subsection{Epitope specificity of OPG antibodies}

To evaluate the antibody response and the epitope specificity, positive coeliac sera for OPG antibodies were selected. Thus, six serum samples were chosen (Coe05, Coe17, Coe18, Coe58, Coe59 and Coe66). The sera reactivity was determined by direct ELISA using the partial recombinant OPG (OPG1 or OPG2). All serum samples were able to recognize both fragments (Figure 4). Antibodies present in the different sera showed different affinity toward OPG1 and OPG2, although this variability was not statistically significant. The tendency observed towards a higher affinity for OPG1 might be due to a greater number of epitopes or more reactive epitopes in this region. In any case these results suggest that the autoantibodies are recognising diverse epitopes throughout the OPG sequence.

In order to quantify the relative affinity of antibodies for OPG fragments, two sera were selected based on their reactivity against OPG, Coe05 and Coe17. A third serum, from the patient where antibodies were described for first time (2), was included as a control. The antibodies' affinity was determined by competitive ELISA and the $\mathrm{IC}_{50}$ and CR were determined for each serum. As shown in figure $5 \mathrm{~A}$, Coe05 presented similar $\mathrm{IC}_{50}$ value for OPG1 and OPG2 (1.45 and $1.44 \mu \mathrm{g} / \mathrm{ml}$, respectively), showing comparable reactivity for both fragments. The control serum presented the greatest affinity for OPG1 $\left(\mathrm{IC}_{50}=0.58\right.$ $\mu \mathrm{g} / \mathrm{ml}$ ) and OPG2 $\left(\mathrm{IC}_{50}=0.88 \mu \mathrm{g} / \mathrm{ml}\right)$. The serum Coe17 showed the least affinity for the fragments with $\mathrm{CR}$ of $\sim 30 \%$ with respect to the most reactive serum. These data showed a range of reactivity, being consistent with previously obtained results by direct ELISA. To analyse if this variability of fragments reactivity is translated in different affinity towards the protein, a competitive ELISA with whole OPG was performed. The Coe05 serum presented an intermediate reactivity with an $\mathrm{IC}_{50}$ of $3.17 \mu \mathrm{g} / \mathrm{ml}$, with the control 
serum again the most reactive for the full protein $\left(\mathrm{IC}_{50}=0.002 \mu \mathrm{g} / \mathrm{ml}\right.$ ) (Figure 5B). Surprisingly the least reactive serum for OPG1 and OPG2, Coe17, did not show any affinity for whole OPG ( $\mathrm{IC}_{50}$ not applicable). It is possible that this serum recognises a cryptic epitope on OPG that is revealed on OPG fragments, but is masked in whole OPG in solution, so being able to bind to the protein in direct ELISA but not in competition assays. Overall the wide range of epitopes recognised and affinities demonstrated indicates a polyclonal antibody response that differs between distinct subjects.

\section{Discussion}

Naturally occurring self-reactive autoantibodies have long been recognized, though their role in normal physiology, as well as in disease pathogenesis, is the subject of ongoing research $(1,18,19)$. We have previously described a case of severe osteoporosis in a patient with coeliac disease that occurred in association with the development of autoantibodies to OPG that were identified using an immunoprecipitation assay (2). This assay is unsuitable for population screening and we note that no significant results were found in a small cohort of 30 coeliac patients screened using this method (20). The current study employed a sensitive and robust enzyme linked immunosorbent assay to detect osteoprotegerin antibodies and identified raised titres of OPG antibody in 7/71 (9.8\%) patients with coeliac disease when compared to $1 / 72(1.4 \%)$ in a control cohort of patients attending an osteoporosis clinic. The threshold used to define a positive test is essentially arbitrary and does not imply any clinical significance in these patients. A significantly lower level of undetectable antibodies found in just 2/71 (2.8\%) coeliac patients, compared to $20 / 72(27.8 \%)$ in the controls is again consistent with this tendency to autoantibody generation in patients with coeliac disease. These results suggest that it is the coeliac disease that drives the generation of the autoantibody response to OPG rather than such antibodies being a consequence of bone disease itself. It is not possible to conclude from our data whether this association relates to the known genetic predisposition to autoimmunity in patients with coeliac disease, or is a direct consequence of coeliac disease (21). Specifically within this cohort we found no correlation with the level of tissue transglutaminase antibody and OPG antibody. We note that OPG antibodies have also been identified in a cohort of patients with rheumatoid arthritis(22).

A significant correlation between OPG antibody titre and hip bone density Z-score is observed, and persists on multivariate analysis including age, sex, height and weight, 
compatible with a pathogenic role for OPG antibodies in a proportion of these patients. No significant correlation was observed between OPG antibody titre and spine bone density however, and we acknowledge that the clinical significance of OPG antibodies has not been established by this data, and that this will need further investigation in a larger cohort.

Studies with recombinant OPG fragments suggested that the autoantibodies generated against whole osteoprotegerin recognise epitopes within distinct regions of the protein, and with widely differing affinities, in keeping with a polyclonal antibody response. The ELISA that we have developed is a useful screening tool for the presence of such antibodies, however both the affinity and epitope specificity of autoantibodies will be important determinants of antibody function. Consistent with this we note that significant functional inhibition of OPG was demonstrated by only 3 out of 6 positive samples for OPG antibodies recently identified using a similar ELISA methodology(22). Serum from the index case was associated with the greatest affinity for both whole OPG and the partial OPG fragments in this study which will in part explain the dramatic phenotype seen. The large $\sim 100$ amino acid fragments of OPG that were used in the current experiments were unable to detect any differential epitope specificity in the serum samples analysed, therefore further work with smaller fragments could be useful to fine map these responses.

\section{Conclusion}

A polyclonal autoantibody response to OPG is identified in patients with coeliac disease. A significant association of OPG antibody titre with lower total hip bone mineral density is compatible with a pathogenic role of OPG antibodies in a subset of these patients, though further work is required to replicate this finding and to establish the clinical utility of testing for OPG antibodies.

\section{Compliance with ethical standards}

The authors would like to acknowledge the generous support of Coeliac UK/Core in funding this work. PLR, SHR and WDF have a patent application pending relating to the detection of osteoprotegerin antibodies in the diagnosis of osteoporosis. PLR reports grants from ECTS and CSO during the conduct of the study; personal fees from IDS and a grant from Menarini outside the submitted work. SHR reports grants from Arthritis Research UK during the conduct of the study, consultancy fees from Merck and Novartis, 
grants from Amgen and Eli Lilly \& Company outside the submitted work. WDF reports fees from IDS, and grants from Roche, Abbott, Siemens and Neotyrix outside the submitted work. JS reports personal fees from Takeda, MSD and Shire outside the submitted work. NK reports grants from Wellcome Trust outside the submitted work. All remaining authors have no disclosures. 
Tables

Table 1. PCR primers used for clone and express three fragments covering the entire OPG protein.

\begin{tabular}{|c|c|c|}
\hline Primer & Description & Sequence (5'-3') \\
\hline F1-F & $\begin{array}{ll}\text { Forward primer } & \text { for } \\
\text { fragment } 1 & \end{array}$ & CCCAGATCTGATGAACAACTTGCTGTGCTGC \\
\hline F1-R & $\begin{array}{l}\text { Reverse primer for } \\
\text { fragment } 1\end{array}$ & GGTG $\underline{C T C G A G T T A G T T G T G G G T G C G A T T G C}$ \\
\hline F2-F & $\begin{array}{ll}\begin{array}{l}\text { Forward primer } \\
\text { fragment } 2\end{array} & \\
\text { frar }\end{array}$ & CCCAGATCTGCGCGTGTGCGAATGCAAGG \\
\hline F2-R & $\begin{array}{l}\text { Reverse primer } \\
\text { fragment } 2\end{array}$ & GGTG $\underline{C T C G A G T T A G A A G A A T G C C T C C T C A C A C}$ \\
\hline F3-F & $\begin{array}{l}\text { Forward primer for } \\
\text { fragment } 3\end{array}$ & CCC $\underline{A G A T C T G A G G T T T G C T G T T C C T A C A A A G}$ \\
\hline F3-R & $\begin{array}{l}\text { Reverse primer } \\
\text { fragment } 3\end{array}$ & GGTGCTCGAGTTATAAGCAGCTTATTTTTAC \\
\hline
\end{tabular}

Table 2. Characteristics of coeliac patients with high titre OPG antibodies

\begin{tabular}{|l|l|l|l|}
\hline Variable & Raised OPG Ab $(\mathbf{n}=7)$ & $\begin{array}{l}\text { Normal OPG Ab } \\
(\mathbf{n}=\mathbf{6 4})\end{array}$ & p value \\
\hline Age & $56.8( \pm 12.9)$ & $60.4( \pm 14.6)$ & 0.54 \\
\hline Female gender & $5 / 7(71.4 \%)$ & $52 / 64(81.2 \%)$ & 0.62 \\
\hline BMI & $28.2( \pm 11.6)$ & $25.5( \pm 4.5)$ & 0.24 \\
\hline Alendronate use & $3 / 7(42 \%)$ & $10 / 64(15 \%)$ & 0.11 \\
\hline $\begin{array}{l}\text { Duration of } \\
\text { disease (months) }\end{array}$ & $141( \pm 161)$ & $120( \pm 115)$ & 0.66 \\
\hline $\begin{array}{l}\text { Prior fragility } \\
\text { fracture }\end{array}$ & $3 / 7(42.9 \%)$ & $21 / 64(32.8 \%)$ & 0.68 \\
\hline Spine T-score & $-1.61( \pm 1.33)$ & $-1.36( \pm 1.25)$ & 0.61 \\
\hline Spine Z-score & $-0.44( \pm 1.47)$ & $-0.19( \pm 1.08)$ & 0.58 \\
\hline Tot Hip T-score & $-1.15( \pm 0.96)$ & $-0.65( \pm 0.99)$ & 0.20 \\
\hline Tot Hip Z-score & $-0.54( \pm 1.26)$ & $0.125( \pm 0.83)$ & 0.06 \\
\hline $\begin{array}{l}\text { Osteoporosis } \\
\text { status }\end{array}$ & $\begin{array}{l}\text { Osteoporosis } 2 / 7 \\
(28.6 \%) \\
\text { Osteopenia } 2 / 7(28.6 \%) \\
\text { Normal 3/7 }(42.8 \%)\end{array}$ & $\begin{array}{l}\text { Osteoporosis } 15 / 64 \\
(23.4 \%) \\
\text { Osteopenia } 17(26.6 \%) \\
\text { Normal 22/64 (34.3\%) }\end{array}$ & 1.0 \\
\hline
\end{tabular}




\section{Figures}

A

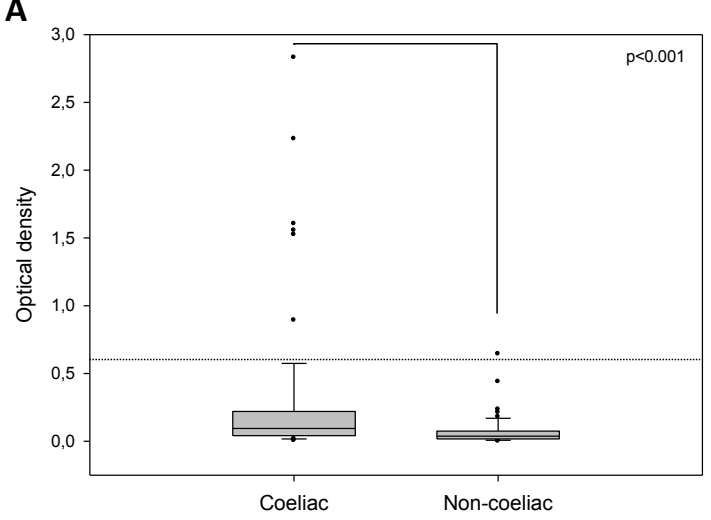

B

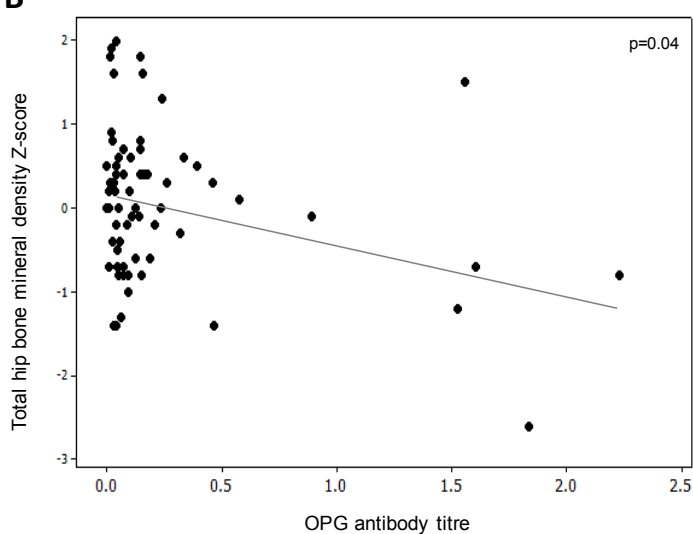

Figure 1. Detection of antibodies against OPG. A. Levels of OPG antibodies in coeliac and non-coeliac patients. Each point represents the mean absorbance - reference value of one patient at OD $450 \mathrm{~nm}$. The threshold for a positive sample is defined as the mean of healthy controls plus 2 standard deviations and illustrated as a horizontal dotted line. B. Regression analysis of OPG antibody levels against total hip bone mineral density Zscore.

A

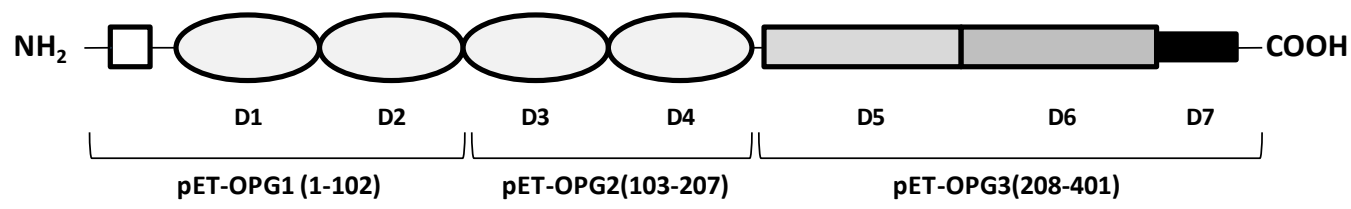

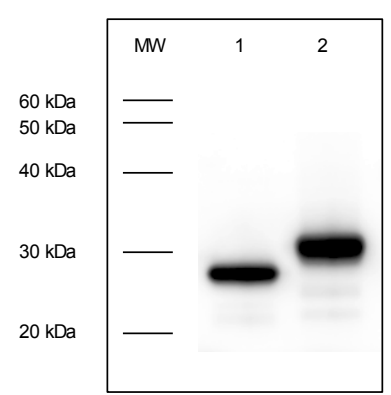

C

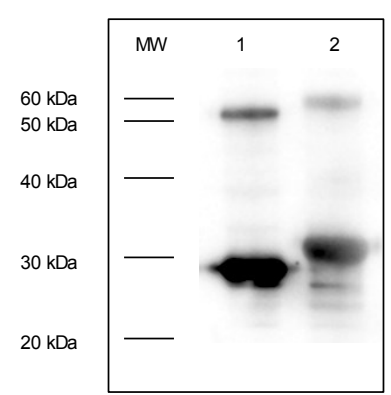

Figure 2. Expression of OPG recombinant fragments. A. Osteoprotegerin protein structure. The different fragments cloned and expressed are shown. B. Western blot analysis of whole cell extract. Membranes were incubated with anti-His moAb. C. Western blot analysis of whole cell extract. Membranes were incubated with anti-OPG pAb. In B and C, lane 1 and 2 are extract of pET-OPG1 and pET-OPG2 respectively. Protein size markers $(\mathrm{kDa})$ are indicated on the left. 
A
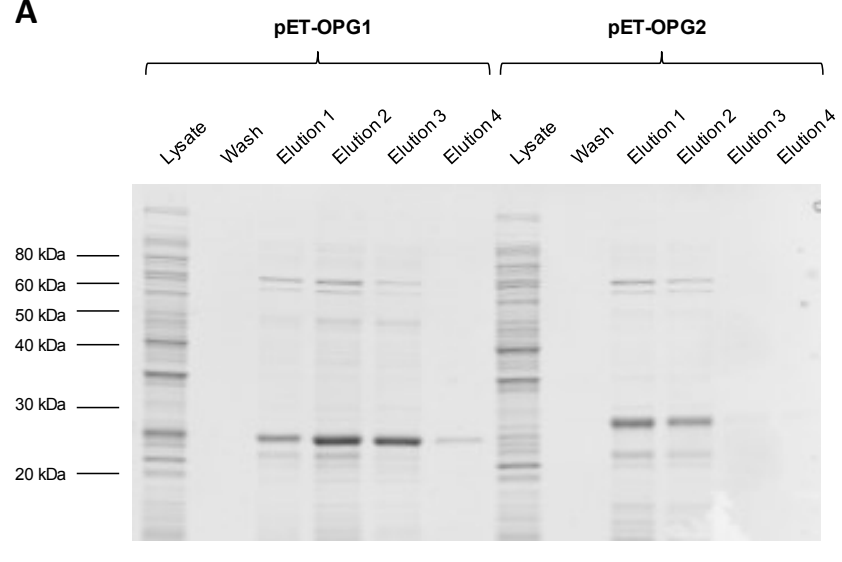

B

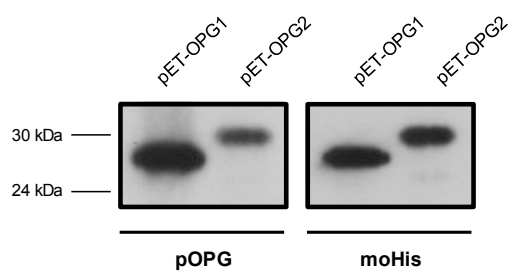

Figure 3. Purification of OPG recombinant fragments. A. Coomassie blue staining of OPG1 and OPG2 purification. Ten microliters of lysate, wash and eluted fractions was analyzed. B. Western blot analysis of fractions pooled by OPG pAb (pOPG) and His moAb (moHis). In $\mathrm{A}$ and $\mathrm{B}$, protein size markers $(\mathrm{kDa})$ are indicated on the left.

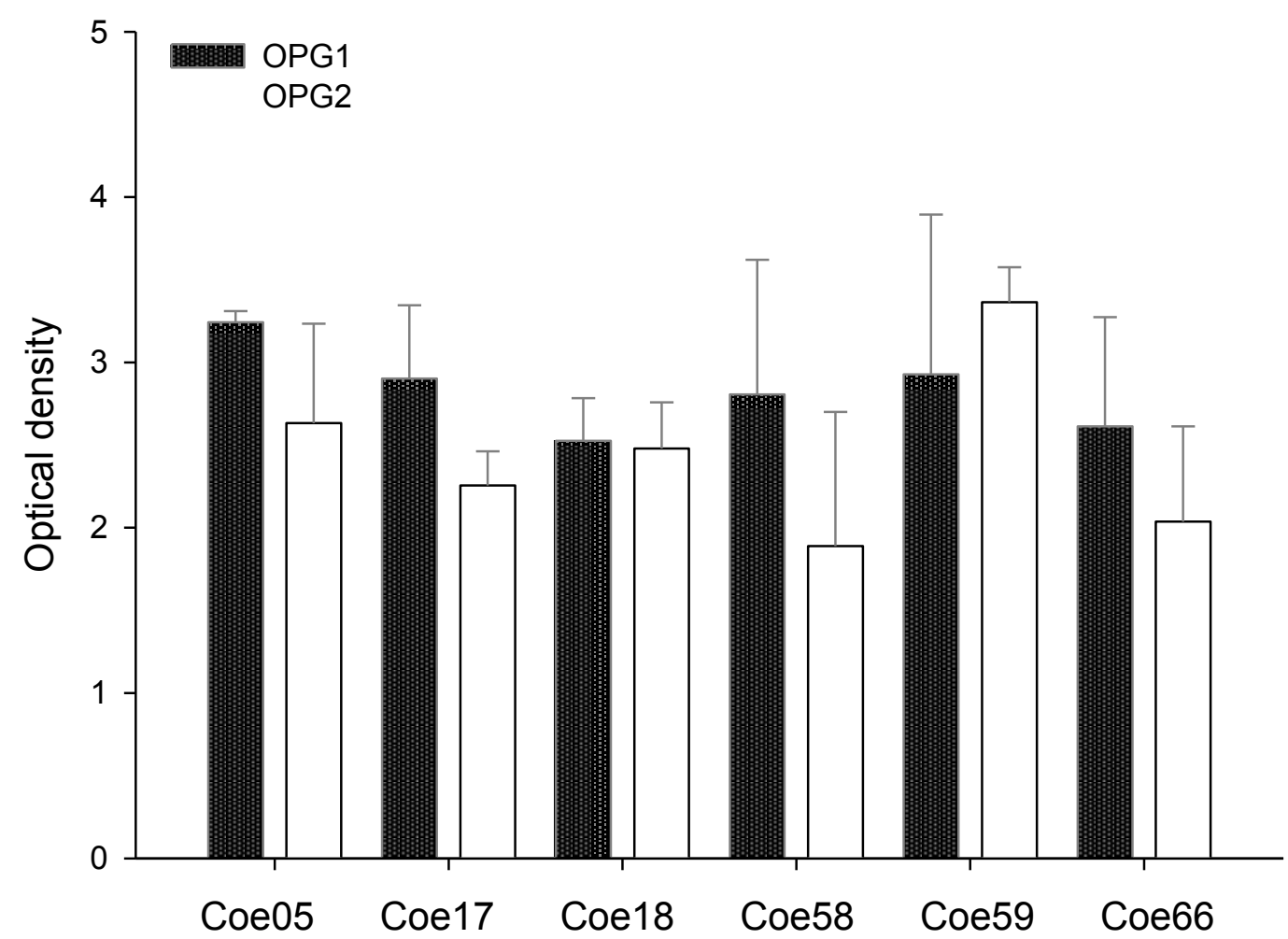

Figure 4. Reactivity of OPG antibodies towards OPG recombinant fragments. Each bar represents the mean absorbance - reference value \pm SD of each serum at OD $450 \mathrm{~nm}$. 
A
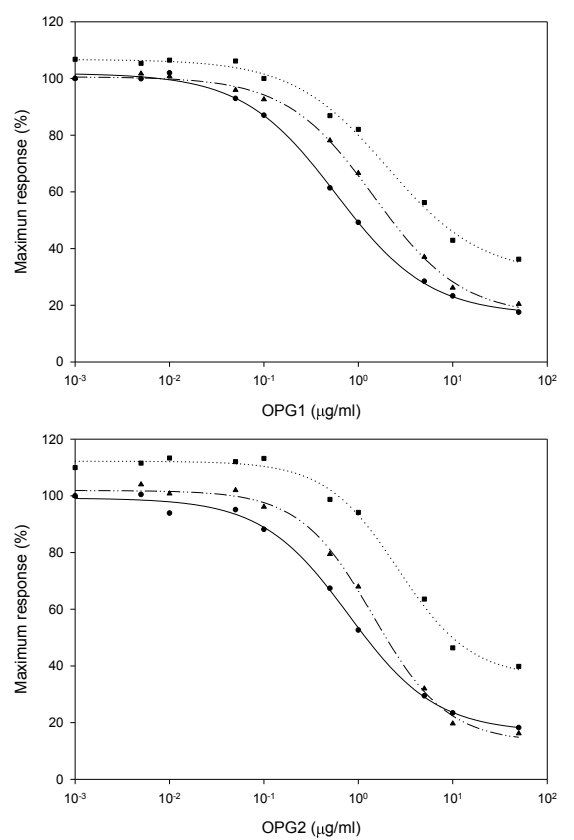

\begin{tabular}{lrrrr} 
& \multicolumn{2}{c}{ OPG1 } & \multicolumn{2}{c}{ OPG2 } \\
\cline { 2 - 5 } & $\begin{array}{r}\text { IC50 } \\
(\mu \mathrm{g} / \mathrm{mI})\end{array}$ & CR $(\%)$ & $\begin{array}{r}\text { IC50 } \\
(\mu \mathrm{g} / \mathrm{m} \text { I) }\end{array}$ & \multicolumn{1}{c}{ CR (\%) } \\
\hline - Control & 0.58 & 100 & 0.80 & 100 \\
- Coe05 & 1.45 & 40 & 1.44 & 55.5 \\
- Coe17 & 2.01 & 28.8 & 2.63 & 30.4 \\
\hline
\end{tabular}

B

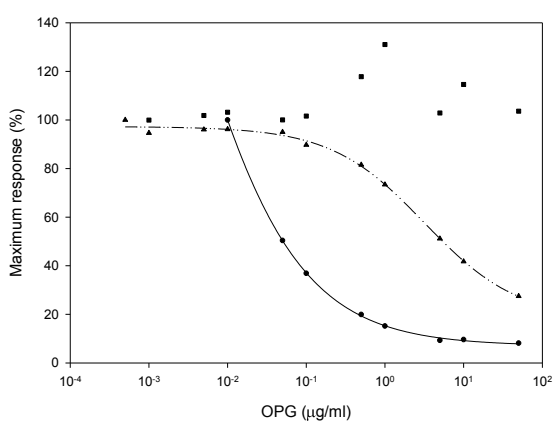

Figure 5. Epitope specificity of OPG antibodies. A. Competitive ELISA to determine the relative affinity of OPG antibodies for the OPG recombinant fragments. IC50 and CR values of each serum to fragments are indicated. •, Control; $\boldsymbol{\Delta}$, Coe05; $\mathbf{}$, Coe17. B. Competitive ELISA to determine the relative affinity of OPG antibodies for OPG. The symbols code is the same as in A. 


\section{Reference List}

1. Browne, S. K., and S. M. Holland. 2010. Immunodeficiency secondary to anticytokine autoantibodies. Curr. Opin. Allergy Clin. Immunol. 10: 534-541.

2. Riches, P. L., E. McRorie, W. D. Fraser, C. Determann, R. v. Hof, and S. H. Ralston. 2009. Osteoporosis Associated with Neutralizing Autoantibodies against Osteoprotegerin. The New England Journal of Medicine 361: 1459-1465.

3. Boyce, B. F., and L. Xing. 2007. The RANKL/RANK/OPG pathway. Curr. Osteoporos. Rep. 5: 98-104.

4. Khosla, S. 2001. Minireview: The OPG/RANKL/RANK System. Endocrinology 142: 5050-5055.

5. Riches, P. L., and S. H. Ralston. 2010. Recent insights into the biology of bone turnover. J. R. Coll. Physicians Edinb. 40: 66-69.

6. McClung, M. R., E. M. Lewiecki, S. B. Cohen, M. A. Bolognese, G. C. Woodson, A. H. Moffett, M. Peacock, P. D. Miller, S. N. Lederman, C. H. Chesnut, D. Lain, A. J. Kivitz, D. L. Holloway, C. Zhang, M. C. Peterson, and P. J. Bekker. 2006. Denosumab in postmenopausal women with low bone mineral density. N. Engl. $J$ Med. 354: 821-831.

7. Chong, B., M. Hegde, M. Fawkner, S. Simonet, H. Cassinelli, M. Coker, J. Kanis, J. Seidel, C. Tau, B. Tuysuz, B. Yuksel, D. Love, and T. Cundy. 2003. Idiopathic hyperphosphatasia and TNFRSF11B mutations: relationships between phenotype and genotype. J. Bone Miner. Res. 18: 2095-2104.

8. Goldring, S. R., and E. M. Gravallese. 2000. Mechanisms of bone loss in inflammatory arthritis: diagnosis and therapeutic implications. Arthritis Res. 2: 3337.

9. Bianchi, M. L., and M. T. Bardella. 2002. Bone and Celiac Disease. Calcif Tiss Int 71: 465-471.

10. Meyer, D., S. Stavropolous, B. Diamond, E. Shane, and P. H. R. Green. 2001. Osteoporosis in a North American adult population with celiac disease. American Journal of Gastroenterology 96: 112-119.

11. Pazianas, M., G. P. Butcher, J. M. Subhani, P. J. Finch, L. Ang, C. Collins, R. P. Heaney, M. Zaidi, and J. D. Maxwell. 2005. Calcium absorption and bone mineral density in celiacs after long term treatment with gluten-free diet and adequate calcium intake. Osteoporos. Int. 16: 56-63.

12. Taranta, A., D. Fortunati, M. Longo, N. Rucci, E. Iacomino, F. Aliberti, E. Facciuto, S. Migliaccio, M. T. Bardella, A. Dubini, M. O. Borghi, S. Saraifoger, A. Teti, and M. L. Bianchi. 2004. Imbalance of osteoclastogenesis-regulating factors in patients with celiac disease. J. Bone Miner. Res. 19: 1112-1121. 
13. Corazza, G. R., S. M. Di, E. Maurino, and J. C. Bai. 2005. Bones in coeliac disease: diagnosis and treatment. Best. Pract. Res. Clin. Gastroenterol. 19: 453-465.

14. Schousboe, J. T., J. A. Shepherd, J. P. Bilezikian, and S. Baim. 2013. 2013 Executive Summary of the 2013 ISCD Position Development Conference on Bone Densitometry. Journal of Clinical Densitometry 16: 455-467.

15. Luan, X., Q. Lu, Y. Jiang, S. Zhang, Q. Wang, H. Yuan, W. Zhao, J. Wang, and X. Wang. 2012. Crystal structure of human RANKL complexed with its decoy receptor osteoprotegerin. J. Immunol. 189: 245-252.

16. Schneeweis, L. A., D. Willard, and M. E. Milla. 2005. Functional dissection of osteoprotegerin and its interaction with receptor activator of NF-kappaB ligand. $J$. Biol. Chem. 280: 41155-41164.

17. Yamaguchi, K., M. Kinosaki, M. Goto, F. Kobayashi, E. Tsuda, T. Morinaga, and K. Higashio. 1998. Characterization of structural domains of human osteoclastogenesis inhibitory factor. J Biol Chem 273: 5117-5123.

18. Nagele, E. P., M. Han, N. K. Acharya, C. DeMarshall, M. C. Kosciuk, and R. G. Nagele. 2013. Natural IgG autoantibodies are abundant and ubiquitous in human sera, and their number is influenced by age, gender, and disease. PLoS. One. 8: e60726.

19. Panda, S., and J. L. Ding. 2015. Natural Antibodies Bridge Innate and Adaptive Immunity. J. Immunol. 194: 13-20.

20. Larussa, T., E. Suraci, I. Nazionale, I. Leone, T. Montalcini, L. Abenavoli, M. Imeneo, A. Pujia, and F. Luzza. 2012. No evidence of circulating autoantibodies against osteoprotegerin in patients with celiac disease. World Journal of Gastroenterology 14: 1622-1627.

21. Denham, J. M., and I. D. Hill. 2013. Celiac disease and autoimmunity: review and controversies. Curr. Allergy Asthma Rep. 13: 347-353.

22. Hauser, B., P. L. Riches, T. Gilchrist, M. R. Visconti, J. F. Wilson, and S. H. Ralston. 2015. Autoantibodies to osteoprotegerin are associated with increased bone resorption in rheumatoid arthritis. Ann. Rheum. Dis. 